\title{
Computer-Aided Coordination and Overcurrent Protection for Distribution Systems
}

\author{
Leon M. Tolbert, Member, IEEE
}

\begin{abstract}
Overcurrent protection and coordination studies for electrical distribution systems have become much easier to perform with the emergence of several commercially available software programs that run on personal computer. These programs have built-in libraries of protective device timecurrent curves, damage curves for cable and transformers, and motor starting curves, thereby facilitating the design of a selectively coordinated protection system which is also wellprotected. Additionally, design time when utilixing computers is far less than the previous method of tracing manufacturers' curves on transparent paper. Basic protection and coordination principles are presented in this paper along with several helpful suggestions for designing electrical protection systems. A stepby-step methodology is presented to illustrate the design concepts when using software for selecting and coordinating the protective devices in distribution systems.
\end{abstract}

\section{INTRODUCTION}

JUST a few years ago, the job of coordinating an electrical $\checkmark$ protection system was a tiresome and tedious task of tracking down manufacturer's published time-current curves and then tracing them on transparent paper. In the design of new electrical distribution systems or in studies performed on existing ones, this laborious task was often left out, especially at the low voltage distribution levels. Now with the advent and proliferation of personal computers, several commercial software programs for performing protection and coordination studies are available for this task. The ease of use of these programs and the benefits derived from conducting a formal protection and coordination study make this a cost effective design approach for all electrical power design projects.

Present protection and coordination software comes with built-in libraries of several manufacturers' complete product lines of circuit breakers, fuses, and relays as well as libraries for cables, transformers, overload elements, and motor starting currents. These libraries may also be customized to add new devices that may be missing from the library. The libraries have the same adjustable settings available that are on the device itself.

One of the greatest benefits of using a graphical computer program for coordination and protection is that time-current curves are displayed on the screen and any changes to equipment settings are updated automatically to see how these adjustments affect the time-current curves. This feature enables better "fine-tuning" of protective device settings in order to achieve the best coordination possible while maintaining protection of the distribution system. Additionally, design time using this software is far less than previous methods of tracing manufacturers' curves on transparent paper. Selecting devices from a built-in library saves the time it would take to either find or obtain the manufacturers' time-current curves, and the curves are generated automatically instead of tracing them or duplicating them by some other means.

Several papers have been written which discuss the topic of coordinating relays in transmission and distribution systems [1-3]. This paper concisely illustrates the basic concepts of protecting a low-voltage electrical distribution system against overcurrents and then shows how to coordinate this protection so that "downtime" and the affected area are both minimized. A step by step method for properly protecting and coordinating an electrical distribution system with the aid of a software program is subsequently outlined. For a more detailed and in-depth look at coordination see IEEE Standard 242-1986 [4].

\section{PROTECTION AND COORDINATION BACKGROUND AND METHODOLOGY}

\section{A. Time-Current Curves}

Fig. 1 represents an example of a time-current curve generated from a computer software program to represent an electrical protection system. Manufacturers of protective equipment and software program developers depict timecurrent curves as a band of values plotted on a $\log$ - $\log$ scale of current in amperes (horizontal scale multiplied by 10 ) versus time in seconds (vertical scale). For a circuit breaker, this band represents the operating time and the device opening time for various overcurrent quantities. For a given current value, the band indicates the minimum and maximum time during which interruption of the circuit is expected. A circuit breaker will stay closed for currents and times to the left and below the band; it will have opened in the region above and to the right of the band. For example, in Fig. 1, for a current of 2,000 A, "MAIN CB" would take between .09 and .11 seconds to open. 


\section{DISCLAIMER}

This report was prepared as an account of work sponsored by an agency of the United States Government. Neither the United States Government nor any agency thereof, nor any of their employees, makes any warranty, express or implied, or assumes any legal liability or responsibility for the accuracy, completeness, or usefulness of any information, apparatus, product, or process disclosed, or represents that its use would not infringe privately owned rights. Reference herein to any specific commercial product, process, or service by trade name, trademark, manufacturer, or otherwise does not necessarily constitute or imply its endorsement, recommendation, or favoring by the United States Government or any agency thereof. The views and opinions of authors expressed herein do not necessarily state or reflect those of the United States Government or any agency thereof. 


\section{DISCLAIMER}

Portions of this document may be illegible in electronic image products. Images are produced from the best available original document. 


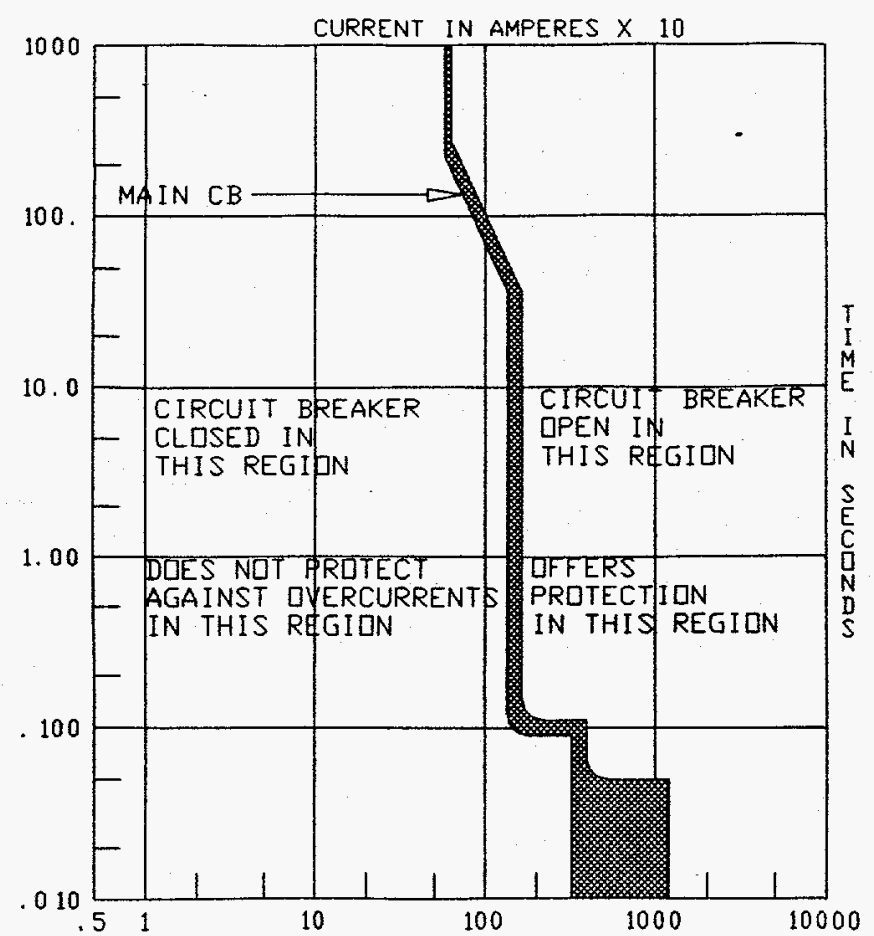

Fig. 1: Time-current curve for a typical static circuit breaker.

Other protective devices such as fuses, motor overloads, and motor circuit protectors may also be represented with timecurrent curves as a band of values. "PRI FUSE", "OVERLOAD", and "MCP" in Fig. 2 depict typical timecurrent curves for a fuse, a motor thermal overload element, and a motor circuit protector, respectively. Time-current curves representing the amount of current that a cable or transformer can withstand before damage to the insulation occurs can also be plotted with these same software programs. In Fig. 3, "CABLE DAMG" represents a cable damage curve, and "TX DAMAGE" is a transformer damage curve. If an overcurrent value is maintained for a duration that crosses the plotted curve, then insulation damage because of overheating or impulse damage has occurred for the subject cable or transformer. "MTR START" is a time-current curve representing the inrush and running current for a typical motor during its initial start and subsequent operation. Software programs enable the motor starting curve to be customized based on full load amperes, inrush or starting current factor, and acceleration time in seconds.

\section{B. Protection Principles}

In order to properly protect the equipment and conductors in an electrical distribution system, protective devices should operate (open) during an overload or short circuit condition prior to the protected equipment sustaining any permanent damage. Represented graphically on a time-current coordination chart, this means that the curve for a circuit breaker or

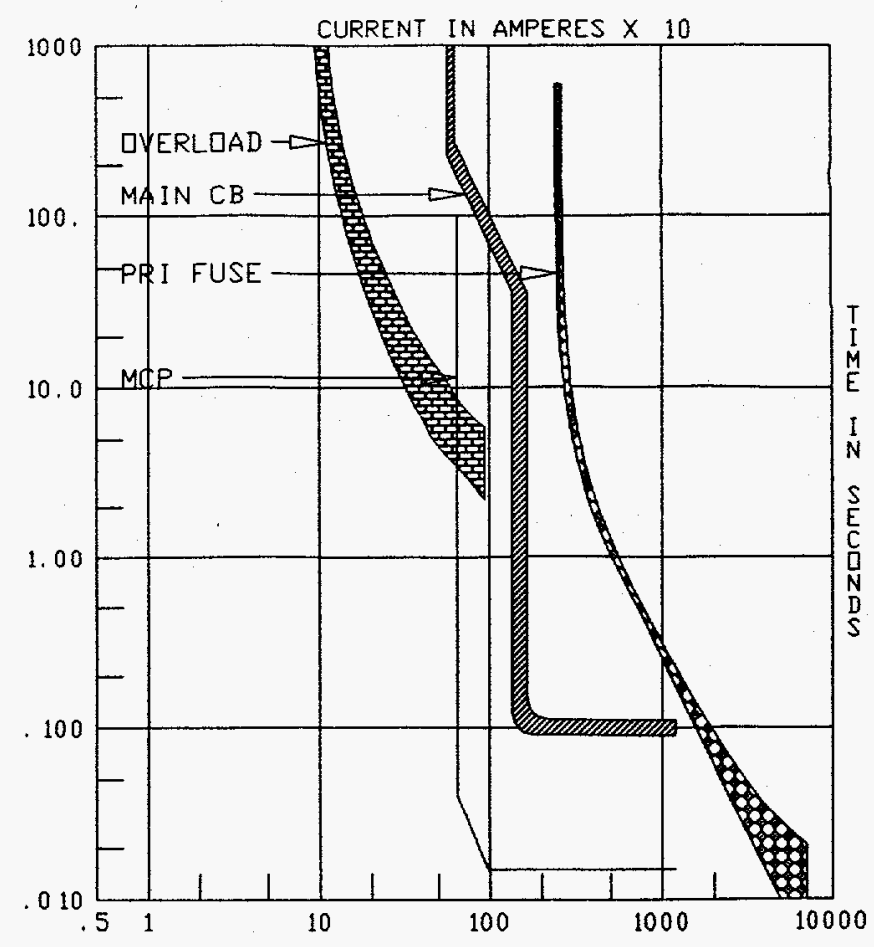

Fig. 2: Time-current curves for various protection devices.

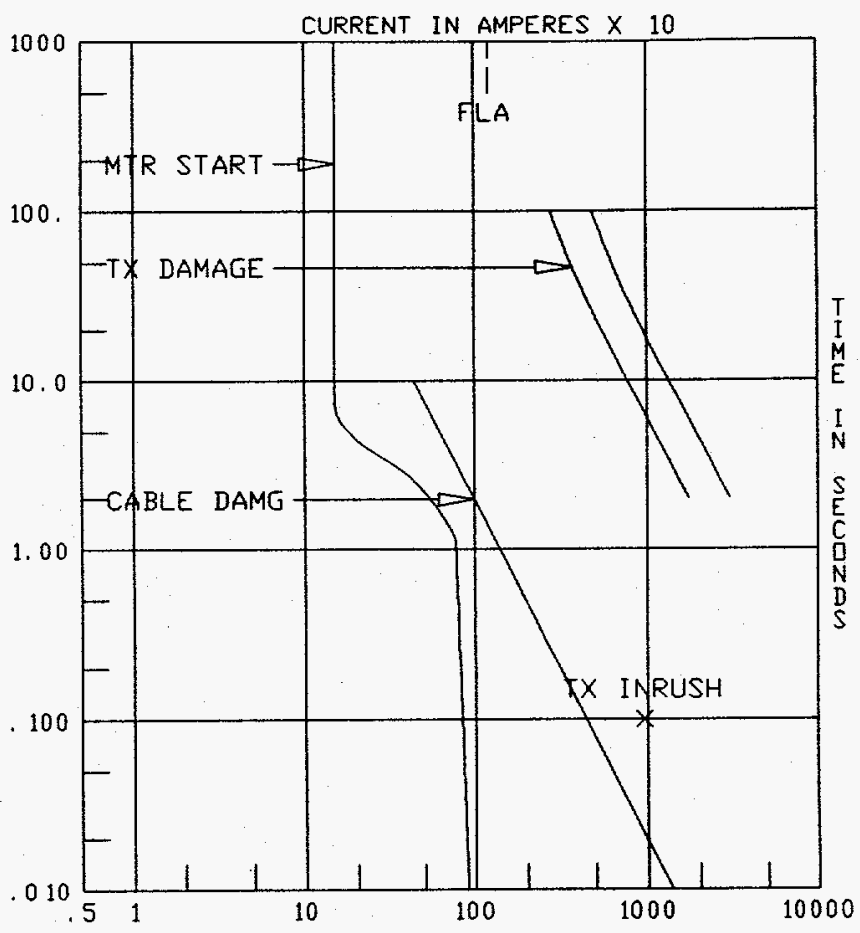

Fig. 3: Time-current curves for equipment damage and motor starting.

fuse must be to the left and below the damage curve for the cable or transformer that it protects. In Fig. 4,"PRI FUSE" is the upstream device which protects a downstream trans- 


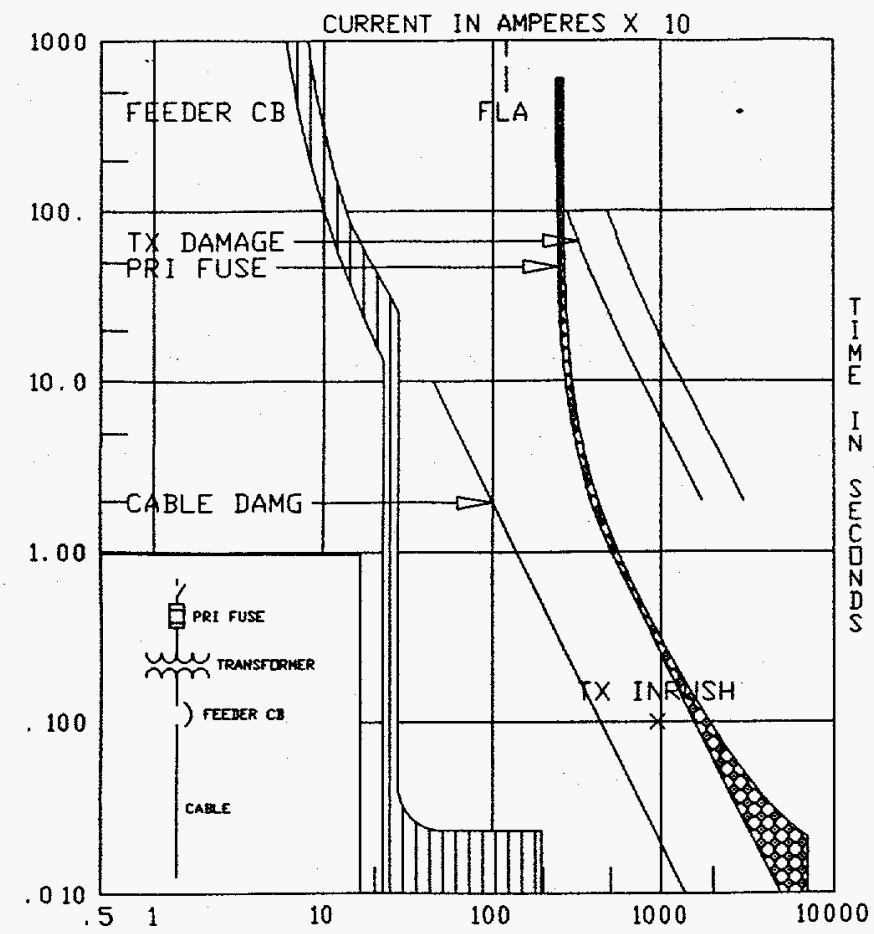

Fig. 4: Time-current curves for proper protection pairs.

former, and this curve is to the left and below the damage curve, "TX DAMAGE", as it should be for proper protection. Another example of a proper protection pair shown in Fig. 4 are "FEEDER CB" and "CABLE DAMG".

Additionally, the time-current curve for a circuit breaker, fuse, or motor overload element must be above and to the right of a transformer's full-load current and current inrush point or a motor starting curve so as to avoid nuisance trips and outages. In Fig. 5, curve "PRI FUSE" is above and to the right of the label "TX INRUSH" in order to avoid opening the fuse when the transformer is energized, and it is to the right of "FLA" to avoid nuisance trips that could be caused by currents that do not exceed the rating of the transformer. In Fig. 5, the curves "MCP" and "OVERLOAD" are to the right of the "MTR START" curve to avoid a nuisance trip when a motor is initially started and accelerated to its normal running speed.

A word of caution is needed at this point. Circuit breakers should not be set to their highest instantaneous pickup or fuses replaced with too high of a full load current rating for the sole purpose of avoiding ANY nuisance trips on the system. Doing so may very well leave equipment unprotected or with little protection at best. Protection curves should be as close to the motor starting and transformer inrush curves as possible without causing nuisance trips; this provides the greatest amount of protection to equipment and personnel.

Selecting the maximum allowed rating according to the

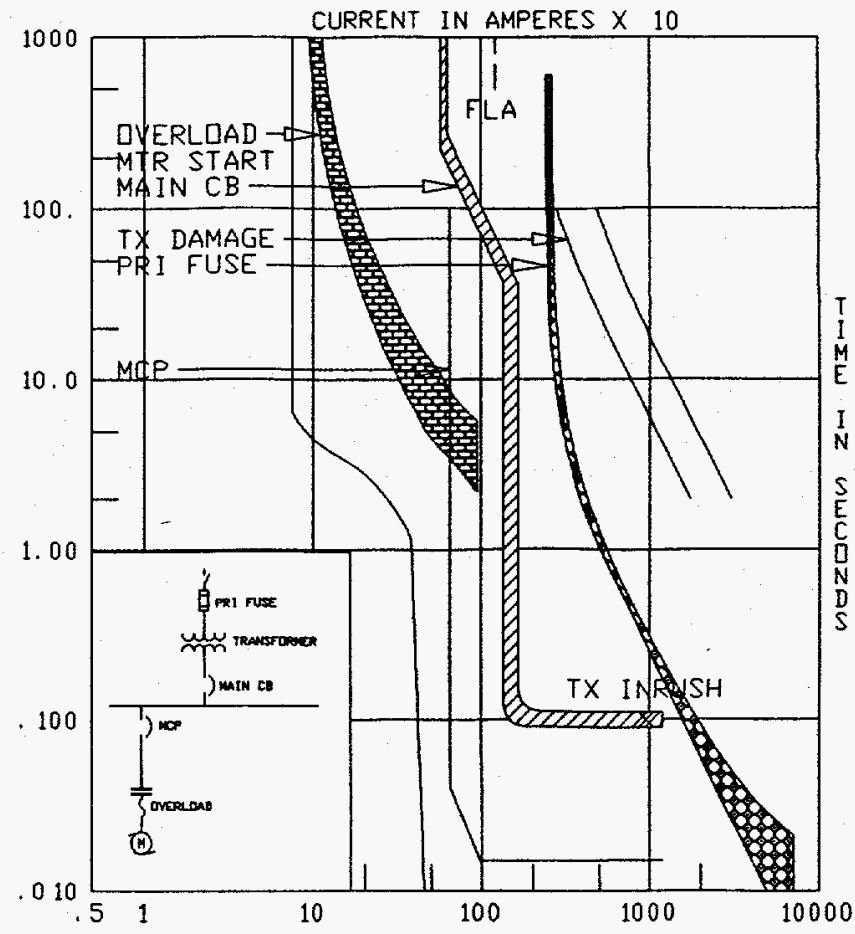

Fig. 5: Avoidance of nuisance trips.

National Electrical Code [5] for protective elements does not always guarantee the best protection and selectivity in a distribution system either. A lower rated fuse or circuit breaker than the maximum allowed by the NEC will often offer better protection and not cause nuisance trips. An accurate model of a motor's starting current and the use of a protection and coordination software program will allow the engineer to determine the required setting of a circuit breaker that offers the best protection possible for that equipment and also coordinates well with other protective devices to selectively open during an overcurrent condition.

\section{Selective Coordination Principles}

To achieve selectivity in the isolation of a fault, protective devices in series must be coordinated such that the upstream device electrically closest to the short circuit or overload opens first to isolate the overcurrent. This minimizes the damage caused by a fault or overload and still allows upstream protective devices (those nearest the source of power) to remain closed and to continue to carry the remaining normal load current. Therefore, coordinated timecurrent curves for electrical protective devices should be "nested" with no overlap to achieve selective isolation of the failure while maintaining normal power to as much equipment as possible. Fig. 5 represents an example of a selectively coordinated system. 


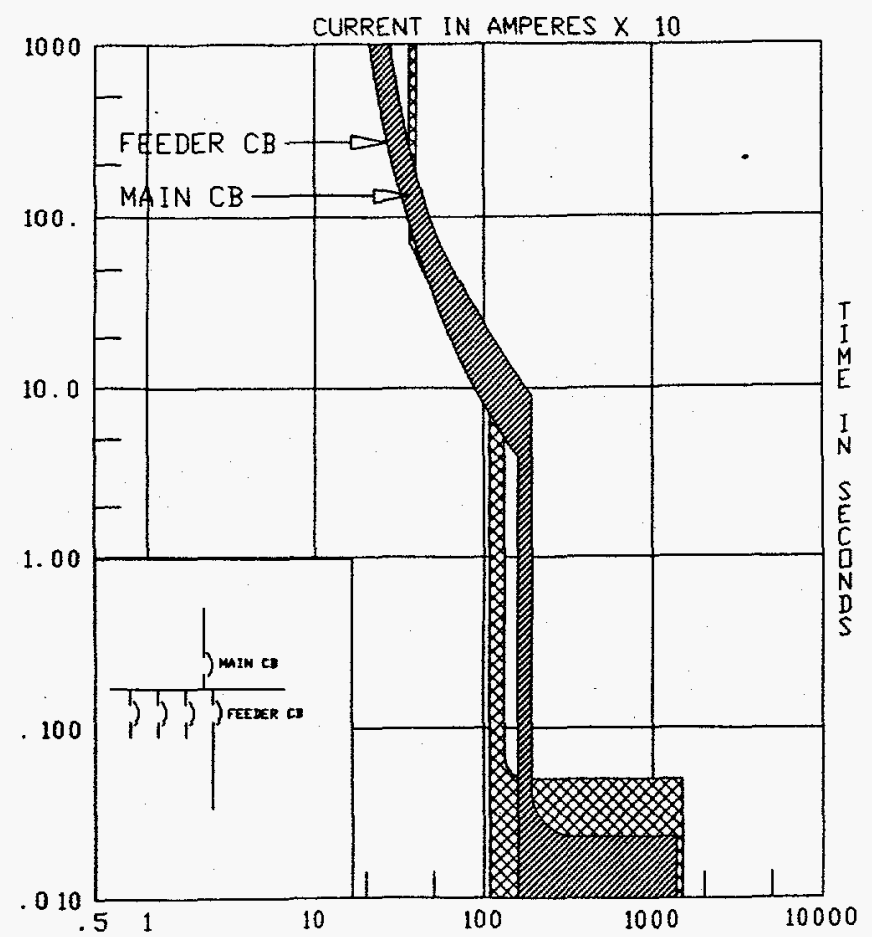

Fig. 6: Time-current curves for improperly coordinated circuit breakers.

Fig. 6 represents an example of a poorly coordinated protective scheme that will achieve much less than the desired results. Note that a large portion of the curves "MAIN CB" and "FEEDER CB" overlap. If a fault of between 500 and 12,000 A occurred downstream of "FEEDER CB", in all likelihood the "MAIN CB" would open first or perhaps both the "MAIN CB" and the "FEEDER CB" would open. This would result in a loss of power to the entire motor control center or distribution panelboard served by the "MAIN CB" and make troubleshooting to find the nature of the electrical anomaly much more difficult and costly. However, these same two circuit breakers can easily coordinate with each other simply by changing the adjustable settings on each one as shown in Fig. 7.

Selecting the same manufacturer for all of the protective devices in an electrical distribution system makes the job of selectively coordinating these devices much easier because manufacturers of these products tend to design their products and any adjustable settings where the time-current curves are easily nested without any overlap. Mix-and-match between several manufacturers makes the task of selective coordination much more difficult.

Selectivity should not be achieved at the expense of loss or severe degradation of protection. There are instances where a small overlap in the time-current curves of two different protective devices may be unavoidable and ideal selectivity cannot be realized. Advances in solid-state technology are making these instances a rarity, however. Many of today's circuit breakers and motor circuit protectors come equipped

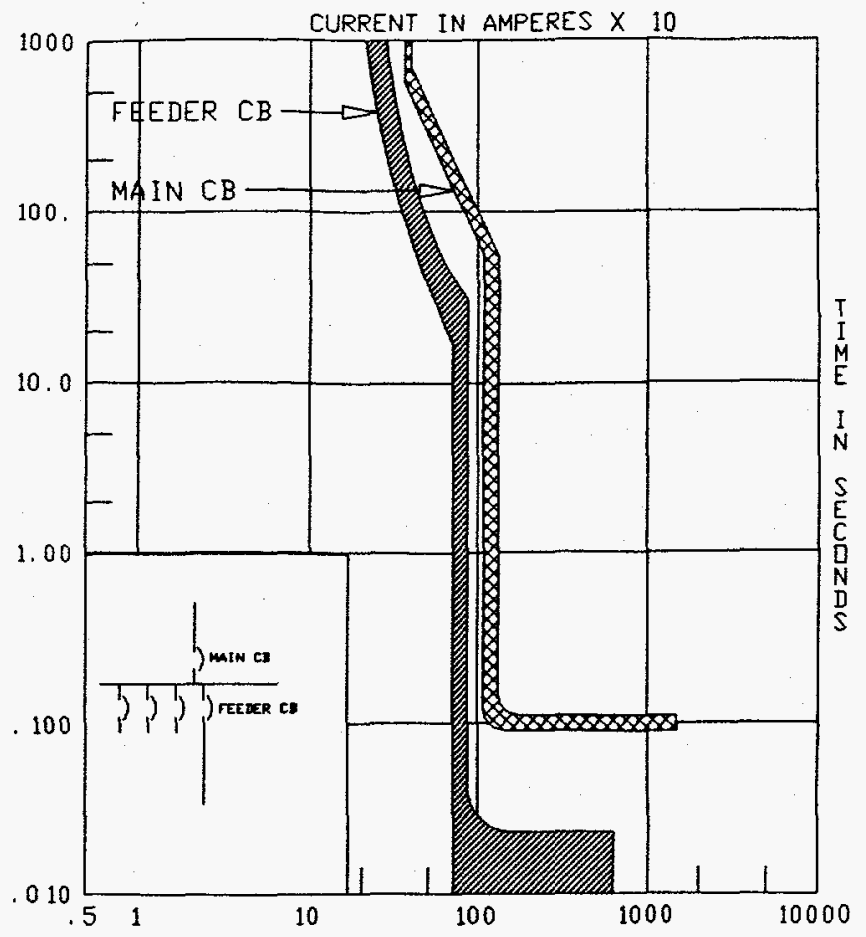

Fig. 7: Time-current curves for properly coordinated circuit breakers.

with solid-state components which have narrow time-current curves. In addition, static circuit breakers usually have several adjustable settings such as long time pickup (percentage of breaker trip rating), long time delay (seconds), short time pickup (multiple of breaker trip rating), short time delay (seconds), and instantaneous pickup (multiple of breaker trip rating) [6]. This leads to better protection of equipment and improved selective coordination with other protective devices in the electrical system. "MAIN CB" in Fig. 5 is an example of a static circuit breaker.

One other cautionary note is that sometimes selective coordination between two protective devices may not always be a primary concern. Suppose the possibility exists that the upstream device of two protective devices in series may open first, but this upstream device may only protect marginally more of the distribution system than the downstream device. As an example, a dedicated feeder to a motor control center and a main in the motor control center may both be protected by similar size protective devices, and this would make selective coordination difficult and perhaps more costly than the expense would justify. Additionally, suppose that the outage of one critical motor would cause an entire process or assembly to be shut down. Then, selectivity between the critical motor's overcurrent protection and the next upstream device may not be of key interest. On the other hand, what would be of importance is ensuring that the protective devices of all the other loads "in parallel" with the critical motor do have selective coordination with the "shared" upstream main protective device to avoid unnecessary outages of the critical motor. 
Even a well-designed protection system will not obtain desired results unless a maintenance program is planned and executed. By periodically electrically exercising protective elements in an electrical system, those devices which operate improperly can either be calibrated or replaced so that they do not fail when they are required to operate under a short circuit or overload condition. Proper maintenance and calibration of the protective equipment will result in a protection system capable of coordinated selective isolation of system faults.

\section{STEPS FOR USING COMPUTER SOFTWARE TO ACHIEVE A Well-Protected, COORDINATEd ElECTriCAL SYSTEM}

1. Draw a one-line diagram for the distribution of the electrical power to the loads.

2. Calculate the maximum available short circuit current at each bus where protective devices are located in the system. Protective devices must have internupting capacities that exceed the maximum available fault current at that bus.

3. Select as a voltage base the predominant voltage in the electrical system.

4. Start with the largest downstream motor or other end-use load first in sizing overloads and circuit breakers or fuses. Work from the bottom of the one-line diagram upstream just as one would in sizing conductors and transformers.

5. In the software program select either a motor starting curve or a cable or transformer damage curve and display it on the time-current curve chart.

6. Check the software program's library of protective devices for the manufacturer of the upstream protective device that you want to use. If contained in the library, choose it and select the adjustable settings so that the downstream equipment is protected from damage from faults or overloads. If the library does not happen to have the specific manufacturer's device, obtain the manufacturer's time-current curves and add the device to the library.

7. Check if the protective device you have chosen is truly protecting downstream equipment (cable, transformer, motor, etc.) If not, select a different rating of the same type of device.

8. Choose the next in series upstream damage curve and protective device from the library of available cable or transformer damage curves and the protective devices.

9. Coordinate overcurrent protection devices so that the one closest to a fault or overload opens first.

10. "Fine-tune" any adjustable settings or sizes so that devices are selectively coordinated AND all equipment is properly protected.

11. Go to the next largest downstream motor or other enduse load and return to step 4 to start a new chart of timecurrent curves.
In an ideal selectively coordinated protection system, only the circuit breaker or fuse closest to a fault or overload condition opens, and the unfaulted portion of the system remains in operation. In addition to providing better personnel protection, this limits the amount of equipment that would be affected by the outage and reduces the chance of critical operations having an interruption of their power source. Use of the steps outlined above in conjunction with one of the commercially available protection and coordination software programs will enable engineers to properly design an electrical distribution system that not only is well-protected but also one that should be relatively free of nuisance trips and limits the amount of equipment affected when a short circuit or overload event does occur.

\section{REFERENCES}

[1] R. Ramaswami, P.F. McGuire, "Integrated Coordination and Short Circuit Analysis for System Protection", IEEE Trans. Power Delivery, Vol. 7, No. 3, pp. 1112-1119, July 1992.

[2] R. P. Graziano, V. J. Kruse, G. L. Rankin, "Systems Analysis of Protection System Coordination: A Strategic Problem for Transmission and Distribution Reliability", IEEE Trans. Power Delivery, Vol. 7, No. 2, pp. 720-726, April 1992.

[3] Y. Y. Hsu, Y. Jwo-Hwu, "Planning of Distribution Feeder Reconfiguration with Protective Device Coordination", IEEE Trans. Power Delivery, Vol. 8, No. 3, pp. 1340-1347, July, 1993.

[4] ANSI Standard 242-1986, IEEE Recommended Practice for Protection and Coordination of Industrial and Commercial Power Systems, 1986.

[5] NFPA Standard 70, National Electrical Code 1993, pp. 90-102, $386,394$.

[6] "Molded Case Circuit Breakers Application and Selection", General Electric, GET-2779G, 1991.

Leon M. Tolbert (S'88-M'91) received the B.E.E. degree in 1989 and the M.S. degree in 1991, both in electrical engineering from the Georgia Institute of Technology, Atlanta.

He worked as a co-op in 1989 for International Business Machines in Lexington, Kentucky, and in 1990 for Ebasco Services in Atlanta. $\mathrm{He}$ is currently employed as a design engineer by Martin Marietta Energy Systems at the Oak Ridge National Laboratory in Tennessee. $\mathrm{He}$ is pursuing a Ph.D. degree in electrical engineering, and his fields of interest include power quality and control of electric machines.

Mr. Tolbert was the recipient of a Prize Paper Award by the Industrial Drives Committee at the IEEE Industrial Applications Society 1991 Annual Meeting. 